\title{
電子サイクロトロン共鳴プラズマスパッタ法による $\mathrm{SnO}_{2}$ ドープ $\mathrm{ZnO}$ 透明導電薄膜の合成*
}

\author{
矢口理英子 $* 1 \cdot$ 佐久間静香 ${ }^{* 1} \cdot$ 上條 榮治*1 \\ （受理1997年11月26日，揭載決定1998年 2 月 7 日）
}

\author{
Preparation of Transparent and Conductive $\mathrm{SnO}_{2}$ Doped $\mathrm{ZnO}$ \\ Thin Films by Electron Cyclotron Resonance Sputtering Method \\ Rieko YAGUCHI*1, Shizuka SAKUMA*1 and Eiji KAMIJO*1 \\ *1 (Faculty of Science and Technology, Ryukoku University, Seta, otsu, 520-21, Japan)
}

(Received November 26, 1997, Accepted February 7, 1998)

\begin{abstract}
Transparent and conductive films of $\mathrm{SnO}_{2}$ doped $\mathrm{ZnO}$ are prepared by electron cyclotron resonance (ECR) sputtering using $\mathrm{ZnO}-(1$ to 30$) \mathrm{mol}_{0} \mathrm{SnO}_{2}$ sintered cylindrical targets in an $\mathrm{Ar}$ atmosphere at various substrate temperatures on glass substrate (Corning 7059). The thin films prepared by sputtering wit a $\mathrm{ZnO}$ target containing $3 \mathrm{~mol} \% \mathrm{SnO}_{2}$ show low resistivity and crystal structures of hexagonal $\mathrm{ZnO}$. The electrical resistivity of as sputterd $\mathrm{SnO}_{2}$ doped $\mathrm{ZnO}$ films when substrate temperature is $473 \mathrm{~K}$ and gas pressure is $2.7 \times 10^{-1} \mathrm{~Pa}$ is $6.43 \times 10^{-3} \Omega \mathrm{m}$ and decreases down to $1.51 \times 10^{-4} \Omega \mathrm{m}$ by a vacuum annealing at $873 \mathrm{~K}$. This film show optical transmission higher than $80 \%$ at an wavelength of $600 \mathrm{~nm}$.
\end{abstract}

\section{1. はじめに}

透明導電薄膜は現在, 薄膜型太陽電池, 凍結防止用, $\mathrm{TFT}$ フラットディスプレイの透明電極などとして広く 用いられている ${ }^{1)}$. 透明導電膜には金属薄膜と酸化物半 導体膜2,3)があるが，金属薄膜は可視光領域に扣ける吸 収が大きく膜強度が弱い等の欠点) があるため今日で は, 酸化物半導体膜が用いられ, ITO $\left(\mathrm{In}_{2} \mathrm{O}_{3}-\mathrm{SnO}_{2}\right)$ が 一般的である5,6). しかしその需要が拡大寸るにつれて, ITO 膜は, 主材料が希少金属の In であるため高価で, 将来材料供給面において安定性の問題や高温での成膜な どの問題が生じてきている.

本研究では, 比較的低温合成が可能な ECR プラズマ

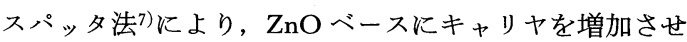
る目的で $\mathrm{SnO}_{2}$ をドープさせた $\mathrm{SnO}_{2}$ ドープ $\mathrm{ZnO}$ 薄膜

$*$ 平成 9 年 11 月 6 日 真空協会第38回真空連合講演会に於いて発表

${ }^{* 1}$ 龍谷大学理工学部 ( $\overline{\mathbf{T}} 520-21$ 大津市瀬田大江町横谷 1-5)
の合成を $\mathrm{SnO}_{2}$ ドープ $\mathrm{ZnO}$ 焼結円筒形ターゲットを用 いて試み，合成した薄膜の諸特性について検討した。

\section{2. 実験方法}

今回実験に用いた ECR プラズマスパッタ装置の概略 図をFig. 1 亿示す。プラズマ室の出口近傍に円筒形 $\mathrm{SnO}_{2}$ ドープ $\mathrm{ZnO}$ 焼結ターゲットを設置し，バイアス 電圧（RF：13.56 MHz) を印加してスパッタを行った. 基板は電気的に浮遊状態にした。詳細な実験条件を

Table 1 と示した.

$$
\text { ターゲットは } \mathrm{ZnO} \text { (純度99.99\%), } \mathrm{SnO}_{2}(99.9 \%) の
$$
市販粉末を CIP $\left(2000 \mathrm{kgf} / \mathrm{cm}^{2}\right)$ で円筒状に成型し, 電 気炉を用いて $1073 \mathrm{~K}, 48$ 時間で焼結したものを使用し た. 合成した膜は, $823 \mathrm{~K}, 5$ 時間のアニール処理を行っ た.

成膜した膜の結晶構造は粉末 $\mathrm{X}$ 線回折装置, 膜の組 成は X 線光電子分光装置, 表面観察は原子間力顕微鏡, 透過率は分光光度計でガラス基板による反射損失を引い 


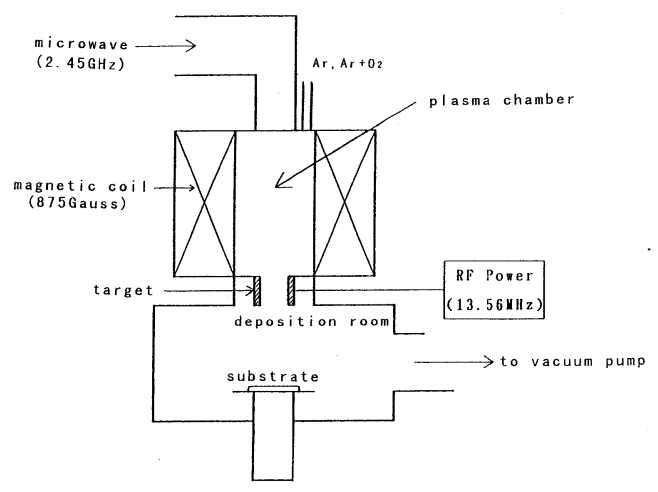

Fig. 1 Schematic diagram of EGR plasma sputtering apparatus.

Table 1 Sputtering conditions

\begin{tabular}{l|l}
\hline \multicolumn{1}{c|}{ Item } & \multicolumn{1}{c}{ Condition } \\
\hline Target material & $\mathrm{ZnO}-1 \sim 30 \mathrm{~mol} \% \mathrm{SnO}_{2}$ \\
Substrate material & Corning $7059 \mathrm{Glass}$ \\
Sputtering gas & pure $\mathrm{Ar}, \mathrm{Ar}+(3 \sim 10 \%) \mathrm{O}_{2}$ \\
Gas pressure & $4.0 \times 10^{-2} \mathrm{~Pa} \sim 2.7 \times 10^{-1} \mathrm{~Pa}$ \\
Microwave power & $400 \mathrm{~W}$ \\
Target voltage & $\mathrm{RF} 50 \mathrm{~W}$ \\
Sub. temperature & $\mathrm{RT} \sim 873 \mathrm{~K}$ \\
\hline
\end{tabular}

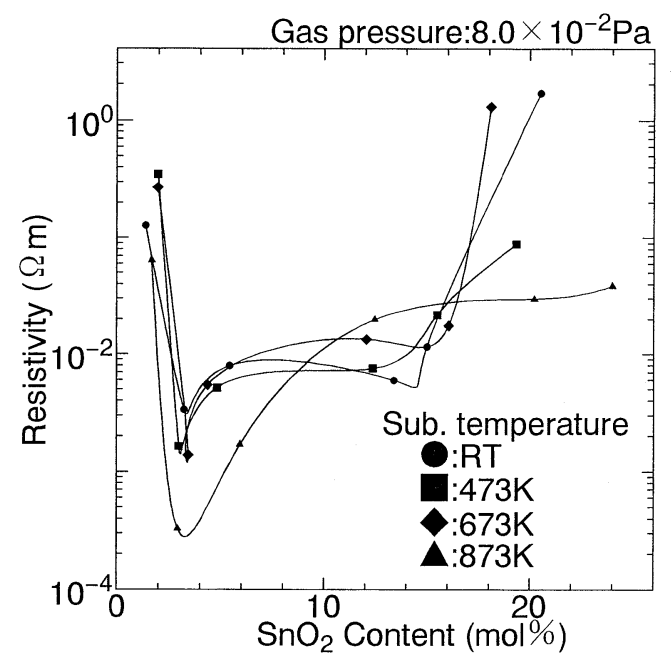

Fig. 2 Composition dependences of electrical resistivity of $\mathrm{ZnO}-\mathrm{SnO}_{2}$ films.

て測定し, 抵抗率は 4 端子法, 膜厚は干渉法を用いてそ れぞれ測定を行った。

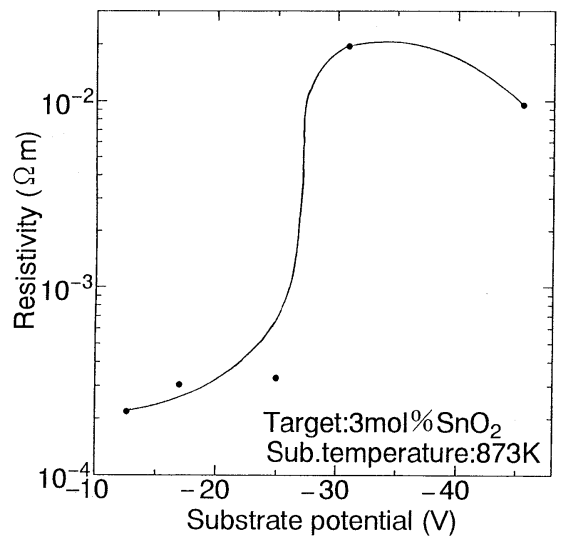

Fig. 3 Relationship between resistivity and substrate potential of the films used Ar sputtering gas.

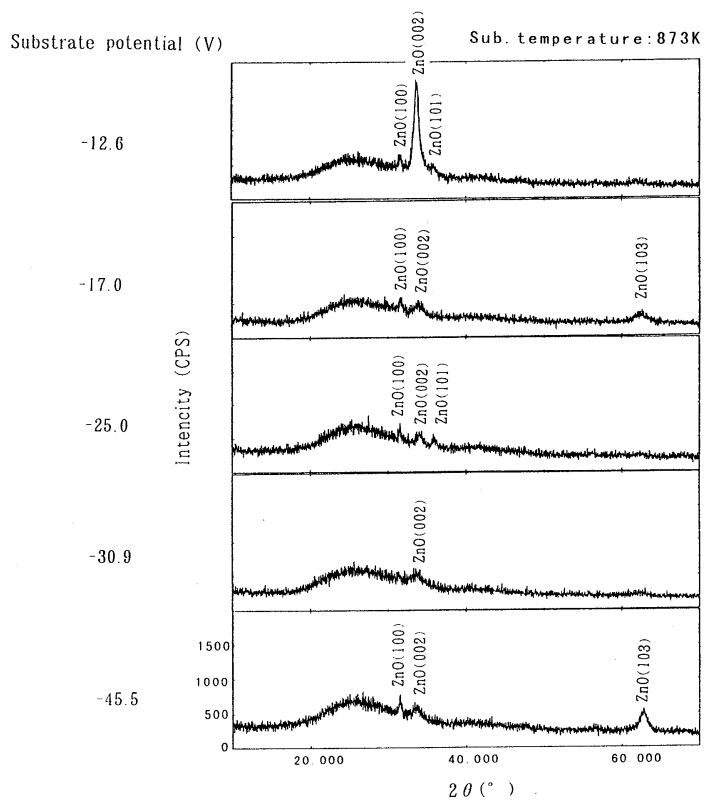

Fig. 4 X-ray diffraction patterns of annealed films prepared with $3 \mathrm{~mol} \%$ target.

\section{3. 結果及び考察}

抵抗率に対する $\mathrm{SnO}_{2}$ の組成依存性を Fig. 2 に示す. どの基板温度に拈いても $3 \mathrm{~mol} \%$ 近辺までは抵抗值が減 少し, $\mathrm{SnO}_{2}$ の増加に従い, 増加していくことがわかっ た. 浮遊状態にある基板電位と膜の抵抗率との関係を Fig. 3 に示寸. 基板電位はガス圧により制御でき，ガス 圧を下げると基板電位が上昇する。この結果から，基板 電位が低い汪ど抵抗率は低く，基板電位が上昇するにつ れて抵抗率も上昇することがわかる。 


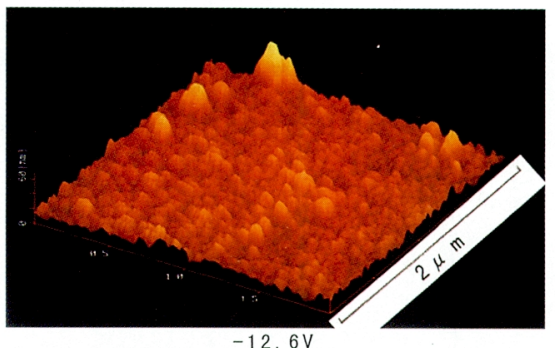

$-12.6$

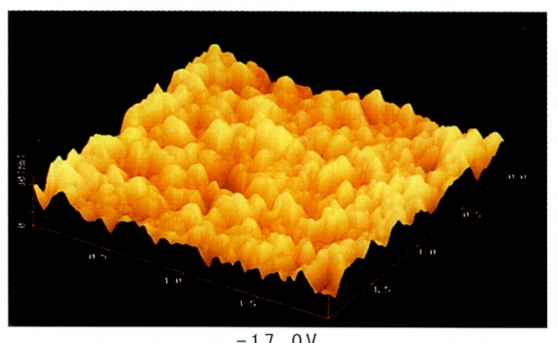

$-17.0 \mathrm{~V}$

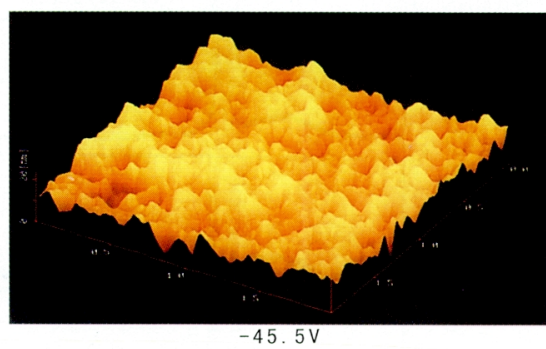

Fig. 5 AFM micrographs of the films deposited with various substrate potential.

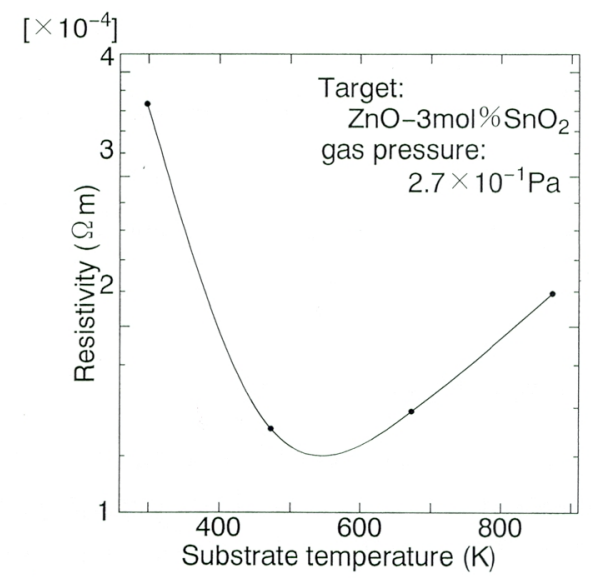

Fig. 6 Relationship between resistivity and substrate temperature.

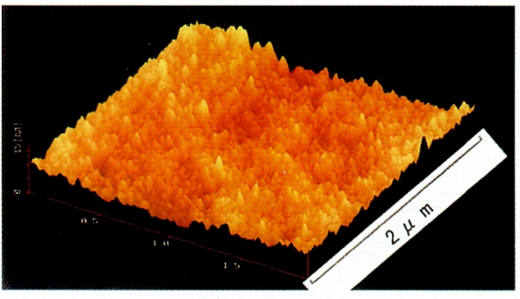

RT

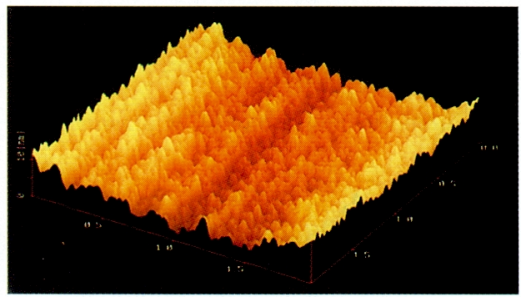

$473 K$

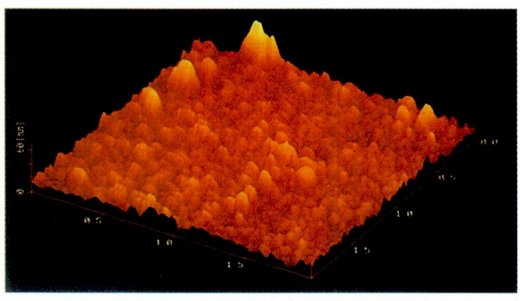

$873 \mathrm{~K}$

Fig. 7 AFM micrographs of the films deposited with various substrate temperature.

基板電位の変化に対する X 線回折の結果を Fig. 4 に 示す．基板電位がー $12.6 \mathrm{~V}$ の時に抵抗率が最も低くな り, $\mathrm{ZnO}(002)$ に配向している ${ }^{8)}$. 配向性は, 基板電位 の増加とともに減少していくことがわかる．合成された 薄膜の表面を原子間力顕微鏡により観察した結果を Fig. 5 に示す。基板電位が負で低いー $12.6 \mathrm{~V}$ では平均 粒径約 $130 \mathrm{~nm}$ の細かな表面微細構造が観察され, 基板 電位の上昇とともに粒子が成長していく様子が観察され る. 抵抗率が上昇する $-45.0 \mathrm{~V}$ では表面構造がそれ以 外に比べてなめらかになっている様子がわかる。これ は，膜への強いイオン衝撃によりスパッタされ結晶構造 がタだれ，抵抗率が上昇したものと考劣られる。

抵抗率に対する基板温度の影響拉よび原子間力顕微鏡 による表面観察の結果を Fig. 6 扎よびFig. 7 に示す. 基板温度が $473 \mathrm{~K}$ 付近で抵抗值は最小の值を示すことが わかった，基板温度が室温では表面が平均粒径約75 nm の微細な粒子で構成されて沶り，基板温度が上昇するに 


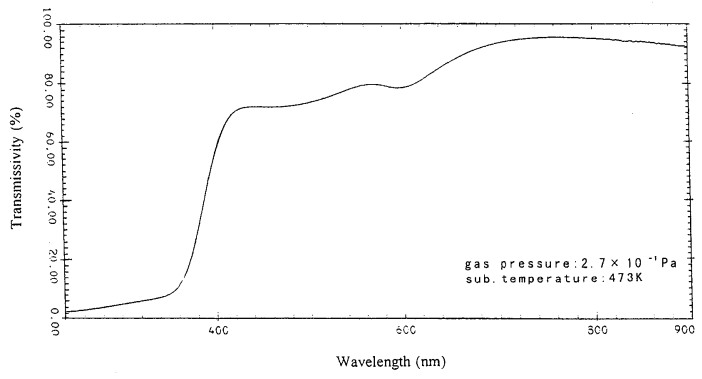

Fig. 8 The transmission spectrum of the $\mathrm{ZnO}-3$ $\mathrm{mol} \% \mathrm{SnO}_{2}$ thin film.

つれ粒子の成長が観察される. 基板温度が $873 \mathrm{~K}$ まで上 昇すると, 他の基板温度に比べ, 粒子の形状がくずれ表 面がなめらかになっていることがわかる. 最も抵抗值が 減少する膜の透過率スペクトルの結果を Fig. 8 に示す. 波長 $400 \sim 600 \mathrm{~nm}$ では平均 $70 \%$ 以上を有し，600 800 $\mathrm{nm}$ では80\%以上の透過率を示した。

\section{4. まとめ}

$\mathrm{ECR}$ スパッタ装置を用いて, 円筒形 $\mathrm{SnO}_{2}$ ドープ $\mathrm{ZnO}$ 焼結ターゲットを用いてスパッタを行い, 得られ
た膜の諸特性を評価して以下の結果が得られた。

(1) 膜の抵抗率は $\mathrm{SnO}_{2}$ 含有量に大きく依存し, その 含有量が $3 \mathrm{~mol} \% \mathrm{SnO}_{2}$ 近傍で最も低い值を示した。

（2）基板電位の減少により，抵抗率は減少した。

（3）ターゲット $\mathrm{ZnO}-3 \mathrm{~mol} \% \mathrm{SnO}_{2}$, 基板温度 $473 \mathrm{~K}$, ガス圧 $2.7 \times 10^{-1} \mathrm{~Pa}$ の成膜条件で $1.51 \times 10^{-4} \Omega \mathrm{m}$ の最も 低い抵抗値が得られた。

（4）波長 $600 \mathrm{~nm}$ での透過率は $80 \%$ 以上を示した.

\section{[文献]}

1）権田 俊一監修：薄膜作製応用ハンドブック（株エ ヌティエス1995） 1032.

2) T. Minami, T. Kakumu and S. Takata: J. Vac. Sci. Technol. A14, 3, (1996) 1704.

3) H. Enoki, T. satoh and J. Echigoya: shys. stat. sol. (a) 126,163 (1991).

4) 榎 浩利：まてりあ第34巻, 第 3 号 (1995) 344 .

5）石橋 暁: 機能材料 vol. 12, No. 6 (1992) 29.

6) R. N. Joshi, V. P. Siugh and J. C. McClure: Thin Solid Films., 257 (1995) 32-35.

7) C. Takahashi, M. Kiuchi, T. Ono and S. Matuo: J. Vac. Sci. Technol, A6, 4 (1988) 2348.

8) M. Ohyama and H. Kozuka, T. Yoko: Thin Solid Films., 306 (1997) 78-85. 